\title{
In Vitro Evaluation of the Physicochemical Effects of Drug Loaded Carbon Nanotubes on Toxicity
}

\author{
Nyaradzo Chigumbu ${ }^{1}$, Sunny lyuke ${ }^{1 *}$, Viness Pillay ${ }^{2}$ and Sehliselo Ndlovu ${ }^{1}$
}

${ }^{1}$ School of Chemical and Metallurgical Engineering, University of Witwatersrand, 1 Jan smut, Braamfontein, 2050 wits, Johannesburg, South Africa ${ }^{2}$ Department of Pharmacy and Pharmacology, University of Witwatersrand, 7 York Street, Parktown, 219 wits, Johannesburg, South Africa

\begin{abstract}
Carbon nanotubes have attracted significant attentions as novel one-dimensional nanomaterials due to their unique structures and properties. Aggregate properties of Carbon Nanotubes (CNTs) such as high surface area, length or surface chemistry are further tailored to enhance their potential application in nanomedicine through post synthesis chemical modifications. These modifications simultaneously alter their aggregate physicochemical properties and this may have a direct impact on cytotoxity of CNTs in cells. Herein, as prepared Multiwalled Carbon Nanotubes (MWCNTs), were initially acid oxidized using strong acids at different temperature to remove impurities whilst introducing carboxylic groups on to the surface. The drug riluzole was then conjugated to the oxidized MWCNTs via carbodiimide activated amidation. Characterized physicochemical properties i.e. length, surface area, degree of functionalization and amount of chemical impurities were key determinants of the drug loaded MWCNTs' cytotoxicity. Covalently linking riluzole to MWCNTs and the consequent changes in the physicochemical properties did not lead to the generation of toxic effects in cells. Furthermore chemically binding riluzole to the MWCNTs did not deactivate the drug and reduce its ability to be antiglutamate. The identification of specific physicochemical properties governing CNT toxicity presents the opportunity for CNT based drug delivery system designs or applications that reduce human and environmental impacts.
\end{abstract}

Keywords: Carbon nanotubes; Functionalization; Toxicity; Drug delivery

\section{Introduction}

Carbon nanotubes (CNTs) are well-ordered, high aspect ratio allotropes of carbon. The bonding in carbon nanotubes is $\mathrm{sp}^{2}$, with each atom joined to three neighbours, as in graphite. The tubes can therefore, be considered as rolled-up graphene sheets (graphene is an individual graphite layer) [1]. The two main variants are Single-Walled Carbon Nanotubes (SWCNTs) and Multi-Walled Carbon Nanotubes (MWCNTs). MWCNTs are larger and consist of many single walled tubes stacked inside the other. Diameters range from 0.7-3.0 $\mathrm{nm}$ for SWCNTs and 10-200 nm for MWCNTs [2]. The length is typically several millimeters though this varies significantly. As a consequence of their small dimensions, CNTs have very high aspect ratios (length to diameter). The available surface area is dependent on length, diameter and degree of agglomeration. Theoretically, unbundled SWCNTs have surface areas of approximately $1300 \mathrm{~m}^{2} / \mathrm{g}$, whereas MWCNTs have a surface area of a few hundred $\mathrm{m}^{2} / \mathrm{g}$ [3].

Amyotrophic Lateral Sclerosis (ALS) is a lethal neurodegenerative disorder characterized by the progressive and selective death of both upper and lower motor neurons [4]. Most ALS patients die from respiratory failure, usually within 3 to 5 years from the onset of symptoms although large deviations have been observed [5]. The annual worldwide incidence of ALS worldwide is between four and nine per 100,000 populations [6]. The economic and social impact of this disease significantly affects healthcare payers (health insurance), patients and their families. There is loss of productivity due to temporary disability, premature retirement or informal care [7].

There is no cure or standard treatment for ALS. The drug riluzole (Rilutek') (Aventis Pharmaceuticals, NJ, USA) is the only prescribed drug approved by the U.S. Food and Drug Administration (FDA) to treat ALS. Riluzole prolongs life of patients with ALS by 2-3 months but does not relieve symptoms [8,9]. The moderate efficacy of riluzole may be due to low bioavailability as a result of the fact that this agent primarily undergoes rapid chemical degradation into its inactive metabolites (e.g. riluzole-glucuronide) in the liver.

The possibility of incorporating carbon nanotubes (CNTs) into living systems has opened the way for the investigation of their potential application in the emerging field of nanomedicine. A drug delivery system is generally designed to improve the pharmacological and therapeutic profile of a drug molecule [10]. Problems associated with the administration of free drugs, such as limited solubility, poor biodistribution, lack of multifunctionality, unfavorable pharmacokinetics, can be overcome and/or eliminated by the use of an efficient drug delivery system. The dispersibility, nanosize, hollow structure, good biodistribution, ability to be multi-functionalized and be target specific renders functionalized CNTs to be potentially novel and effective delivery vehicles.

Indeed, for successful ALS therapy an efficient riluzole delivery system is required. This will allow for an increased bioavailability and reduce the adverse effects which sometimes lead to discontinuation of the drug. From previous work it has been shown that CNTs have the capability to easily and rapidly translocate into cellular components in a non-invasive way $[11,12]$. Drug loaded CNTs therefore present an opportunity for the enhancement of the cellular uptake and consequently transport and biodistribution of therapeutic agents without displaying cytotoxicity.

*Corresponding author: Sunny lyuke, School of Chemical and Metallurgical Engineering, University of Witwatersrand, Jorrisen Street, 2050 wits Johannesburg, South Africa, Tel: +27-11-717-7546; Fax: +27-11-717-7591; E-mail: sunny.iyuke@wits.ac.za

Received March 30, 2012; Accepted May 15, 2012; Published May 19, 2012

Citation: Chigumbu N, lyuke S, Pillay V, Ndlovu S (2012) In Vitro Evaluation of the Physicochemical Effects of Drug Loaded Carbon Nanotubes on Toxicity. $J$ Nanomed Nanotechol 3:135. doi:10.4172/2157-7439.1000135

Copyright: (c) 2012 Chigumbu N, et al. This is an open-access article distributed under the terms of the Creative Commons Attribution License, which permits unrestricted use, distribution, and reproduction in any medium, provided the original author and source are credited. 
With a multitude of opportunities for carbon nanotube use in pharmaceutical and medical applications, a thorough understanding of associated systemic toxicity is critical. Common purification and functionalization of CNTs significantly and simultaneously modify their physicochemical properties such as dispersivity in solution, length, chemical composition and surface area. There is a correlation between cytotoxicity and these physicochemical properties that enhance CNTs to cell contact opportunities [13]

A lot of research has been done towards the toxicity of CNTs. Studies have implicated aspect ratio [13], CNTs length [14,15], surface area $[16,17]$, bioavailability $[12,18]$ and co-contaminants from synthesis $[19,20]$ as sources for potential toxicity. When particles (e.g., CNTs) have entered the body system, the clearance of the deposited particles in the body basically involves two processes, physical translocation and chemical dissolution via phagocytosis by alveolar macrophages. However, depending on their particle size, chemical composition and bioavailability, the phagocytosis may become ineffective leading to accumulation of the CNTs which may then interact with cellular components, disrupt or alter cell functions [21]. Previous studies have concentrated on the impact of attaching a drug to CNTs on cell viability and whether the CNTs enter cells in an invasive manner and not on the effects of the physicochemical modifications that arise due to the linking of drugs to CNTs $[12,21,22]$. Wu et al. [12] found that the antifungal drug, AmB covalently linked to CNTs is taken up by mammalian cells without presenting any specific toxic effect but did not relate the toxicity to the physicochemical characteristics of the AmB-CNT conjugates.

Past toxicity assessments have also differentiated between single walled and multiwalled carbon nanotubes but only a few have investigated the effects of physical and chemical characteristic modification when reporting the toxicity [13,16,17]. Analysis of CNT toxicity is complicated as it draws upon studies with vastly different synthesis technique, solution chemistry and sample purity. Material characterization, standardized toxicity assays and careful documentation of studies of the correlation between cytotoxicity and physicochemical properties of CNTs will be fundamental to a mechanistic understanding of nanotube toxicity [13].

Therefore, the aim of this study is to give a detailed characterization of the physical and chemical properties of riluzole loaded Multiwalled Carbon Nanotubes (riluzole-MWCNTs) and correlate it to toxicity to elucidate a better understanding of CNTs toxicity. Comparisons are made of the toxicity in neuronal cells of riluzole loaded MWCNTs made following purification under varying acid oxidation temperatures.

\section{Materials and Methods}

\section{Materials}

All the reagents were used without further purification. Riluzole, Ferrocene, and Diisopropylcarbodiimide were purchased from Sigma (St. Louis, USA). Dimethylformamide, sulphuric acid, nitric acid, methanol and Sodium hydroxide were purchased from Merck chemicals (Johannesburg, South Africa). The Neural cell line was purchased from Health Science Research Resources Bank (Japan). The RPMI-1640 medium, fetal bovine serum and horse serum were purchased from Sigma (St. Louis, USA). Penicillin/streptomycin was purchased from Highveld Biology (Johannesburg, South Africa). Acetylene and Argon were purchased from Afrox (Johannesburg, South Africa). The Cytotox-96 non-radioactive cytotoxicity assay was purchased from Promega (Madison, USA).

\section{Production of the riluzole loaded MWCNTs}

The CNTs were synthesized using the vertical Catalytic Chemical Vapor Deposition (CCVD) according to the procedure described by Iyuke et al. [23] with minor alterations. Acetylene was used as the carbon source and Ferrocene $(10 \mathrm{mg})$ as the catalyst. The reactor was operated at temperatures of about $900^{\circ} \mathrm{C}$ for a reaction time of 20 minutes.

The synthesized MWCNTs were then oxidized in $400 \mathrm{ml}$ of a mixture of sulfuric acid and nitric acid in a composition of $3 / 1$ by volume to allow for the removal of metallic impurities (catalysts and fullerene particles) and opening of tips. This process also led to the generation of carboxylic groups (COOH) on the CNTs walls [24]. The mixture was initially sonicated in a water bath for 10 minutes at room temperature and was then heated at $100^{\circ} \mathrm{C}$ for 1 hour to conduct the acid treatment. Other conditions of acid treatments included $60^{\circ} \mathrm{C}$ for 6 hours and $40^{\circ} \mathrm{C}$ for 24 hours. At the end of acid treatment, each mixture (now defined as $o x-\mathrm{MWCNT}_{@ 100}, o x-\mathrm{MWCNT}_{@ 60}$ and $o x-\mathrm{MWCNT}_{\odot 40}$ respectively) was washed with distilled water till the supernatant had a neutral $\mathrm{pH}$ and dried at room temperature for one day.

Acid-base titration of $o x$-MWCNTs was used for the quantification of surface functional groups, more specifically carboxylic acid group $(\mathrm{COOH})$ [25]. Ox-MWCNTs $(50 \mathrm{mg}$ ) were added into a $25-\mathrm{ml} 0.04 \mathrm{~N}$ sodium hydroxide $(\mathrm{NaOH})$ solution in a $100 \mathrm{ml}$ flask. The flask was sealed and placed in a shaking incubator at $25^{\circ} \mathrm{C}$ at $150 \mathrm{rpm}$ for 48 hours. The dispersion was then filtered. The filtrate was titrated with a $0.04 \mathrm{~N}$ standardized $\mathrm{HCl}$ solution to a $\mathrm{pH}$ of 7 to determine the excess $\mathrm{NaOH}$ in the solution and the concentration of the $\mathrm{COOH}$ on the $o x-$ MWCNTs.

Riluzole was conjugated to the ox-MWCNTs using the carbodiimide-activated amidation. In a typical experiment $o x$ MWCNTs (100 mg, mmols depends on the temperature of oxidation, Table 1) was dispersed into $20 \mathrm{ml}$ Dimethylformamide (DMF) in a $100 \mathrm{ml}$ flask. Riluzole $(1.5 \mathrm{x}[\mathrm{COOH}] \mathrm{mg}$ depend on the ox-MWCNTs sample used, Table 1) dispersed in $5 \mathrm{ml}$ DMF was then added to the CNTs and the mixture stirred at room temperature for 3 hours. During the reaction, the coupling reagent Diisopropylcarbodiimide (DIC) (1 $\mathrm{x}[\mathrm{COOH}]$, volume depends on the $o x$-MWCNTs sample used, Table 1) in $5 \mathrm{ml} \mathrm{DMF}$ was gradually added. After the 3 hours the reaction mixture was centrifuged at $7000 \mathrm{rpm}$ and the solid product was washed three times with methanol to remove excess drug. The solid product (now defined as riluzole-MWCNT ${ }_{@ 40}$, riluzole-MWCNT ${ }_{@ 60}$ and riluzole-MWCNT $\mathrm{MW0}$ ) was dried at room temperature for 24 hours.

\section{Characterization}

Transmission Electron Microscopy (TEM) was used to provide the visualization information on tube dimensions, purity, morphology and level of aggregation (Jeol JS-100 at $80 \mathrm{kV}$ ).Fourier transform infrared ((FTIR, Perkin Elmer, Spectrum One) spectrometer was used to verify the formation of amide bonds and therefore the success of conjugation in the riluzole-MWCNTs. This was further confirmed by the UV vis spectrophotometer. Raman spectroscopy was used to provide the structural characteristics of the carbon nanotubes and an indication of the degree of functionalization. Surface area of the riluzole-MWCNTs conjugates was characterized by the BET analyzer.

\section{Cell cultures and cell culture tests}

Cell cultures: PC 12 neuronal cell line was cultured in RPMI 1640 media (Sigma Aldrich) supplemented with 5\% fetal bovine serum, 10\% 
horse serum(both heat inactivated), and $1 \%$ penicillin/streptomycin. Cells were grown in suspension in an incubator with humidified atmosphere with $5 \% \mathrm{CO}_{2}$ at $37^{\circ} \mathrm{C}$.

Cellular uptake: For the translocation test, cell suspensions were prepared at a final concentration of 10,000 cells $/ \mathrm{ml}$ in $1 \mathrm{ml}$ media containing FITC labelled riluzole loaded CNTs. The concentrations of MWCNT-riluzole-FITC were $0.002,0.02$ and $0.2 \mathrm{mg} / \mathrm{ml}$. Untreated cells and unconjugated FITC were used as controls. The cells were incubated at $37^{\circ} \mathrm{C}$ for 1 hour. After incubation the cells were washed twice in phosphate buffered saline (PBS), resuspended in $300 \mu \mathrm{l}$ PBS, loaded on to a 96 well plate and analyzed with the victor X3 UV-vis mode at a wavelength of $492 \mathrm{~nm}$. The distribution of FITC was given in terms of absorbance units. The media and untreated cells were used as controls.

Physicochemical effects of drug loaded CNTs on cell viability: To determine the correlation between the physicochemical effects of drug loaded CNTs and cell viability, PC12 neuronal cell suspensions were prepared at a final concentration of 10,000 cells $/ \mathrm{ml}$ in media, containing riluzole-MWCNT ${ }_{@ 40}$, riluzole-MWCNT $\mathrm{M60}$ and riluzole-MWCNT ${ }_{\oplus 100^{\circ}}$ Concentrations used were $0.002,0.02$ and $0.2 \mathrm{mg} / \mathrm{ml}$. Apart from the test compound control, the following controls were also used, (1) nocell background control and (2) untreated cells control. The cells were incubated at $37^{\circ} \mathrm{C}$ for 24 hours in a 96 well plate. After incubation, all the cultures were gently centrifuged and sample supernatants were collected for quantitatively measuring Lactate Dehydrogenase (LDH).

Treatment of Neuronal Cultures with Glutamate: Cultured PC12 neuronal cells were pre-incubated with riluzole-MWCNT ${ }_{@ 100}$ and free riluzole as a control for 1 hour at room temperature before Glutamic acid (Glu) treatment. Riluzole-MWCNT ${ }_{₫ 100}$ and free riluzole were present throughout the Glu treatment at concentrations $0.1,1$ and 10 $\mu \mathrm{M}$. For Glu treatment, cultured neurons were stimulated with 0.25 $\mathrm{mM}$ Glutamic acid for 5 minutes. The stimulation was terminated by removal of the Glu-containing medium. Cultures were further washed twice and incubated with serum-free RPMI 1640 for 24 hours at $37^{\circ} \mathrm{C}$ to allow the process of neuronal injury to be completed. Controls used included acid oxidized MWCNTs, free riluzole, untreated cells for spontaneous LDH release correction and cells treated with Glu in the absence of the test materials for maximum LDH release. After incubation all the cultures were gently centrifuged, sample supernatants were collected for quantitatively measuring Lactate Dehydrogenase (LDH).

LDH assay: Released LDH in culture supernatants was measured with CytoTox 96 Non-Radioactive Cytotoxicity Assay. CytoTox $96^{\circ}$ Non-Radioactive Cytotoxicity Assay and reagents to quantitatively measure lactate dehydrogenase (LDH) were prepared and added as directed by the manufacturer. Released LDH in culture supernatants was measured with a 30-minute coupled enzymatic assay, which results in the conversion of a tetrazolium salt (INT) into a red formazan product which is catalyzed by the LDH released from cells and diaphorase present in the assay substrate mixture. The amount of color formed is proportional to the number of dead cells. Visible wavelength absorbance data was then collected using a standard 96-well plate reader at $490 \mathrm{~nm}$ wavelength (formazan is detected at wavelength of $490 \mathrm{~nm}$ ). The data was presented as a percentage of the untreated cells control.

\section{Statistical analysis}

Results were calculated as the mean \pm Standard deviation of the triplicate experiments. The significance of the results was statistically analyzed by a two-way analysis of variance (ANOVA). Statistical significance was set at $\mathrm{P}<0.05$.

\section{Results and Discussion}

\section{Physicochemical characterization of the riluzole loaded MWCNT and its precursors}

From the TEM images (Figure 1), both as-prepared and acid treated MWCNTs were free of amorphous carbon. Neither loosely bound clusters nor a thin layer attached to the outer surface of MWCNTs could be observed. TEM imaging (Figure 1) confirms the reduction of catalytic metal aggregates. The catalyst particles and support material, which showed dark contrast, thickly covered the CNTs for as prepared MWCNTs (Figure 1(a)), but they were significantly reduced for the $o x$-MWCNTs (Figure 1(b)-(d)). Most of the dark spots on low magnification image are due to nanotube endings aligned parallel to the electron beam. The harsh chemical conditions necessary for introducing functional groups affected the physical properties by cleaving the nanotubes and introducing structural defects.

TGA of purified samples, which was carried out in air, revealed a significant drop of mass at about 650 to $800^{\circ} \mathrm{C}$. This weight loss was correlated with the decomposition of MWCNTs via oxidation (inflexion point of TGA curve, Figure 2), as the characteristic combustion temperature of disordered carbon usually emerges at around $400^{\circ} \mathrm{C}$ [26]. This result complemented the TEM result that amorphous carbon was absent in both prepared and acid oxidised CNTs.

Table 2 shows information on the CNT purity obtained from the TGA based on the extent of non-oxidizable residue at high temperature
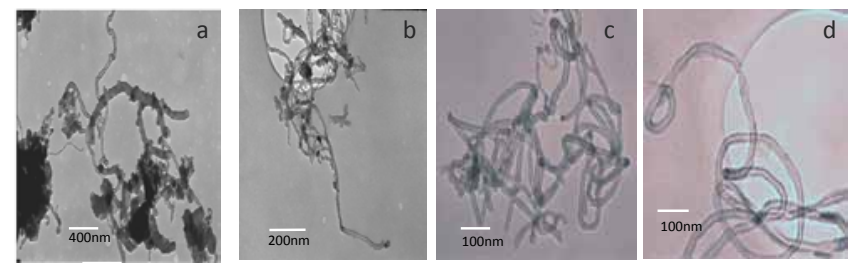

Figure 1: TEM images of a) as prepared b) ox-MWCNT ${ }_{@ 40}$ c) ox-MWCNT

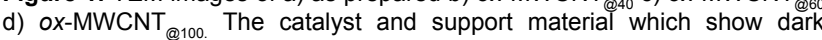
contrast, are thickly covering CNTs for (a) and are seen to reduce with increase in acid oxidation and purification temperature from (b)-(d). The dark spots in image (c) and (d) are mainly due to nanotube endings aligned parallel to the electron beam.

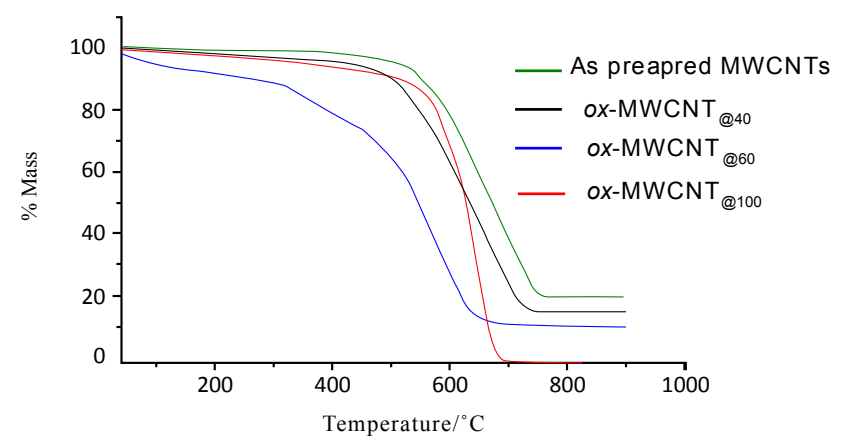

Figure 2: TGA curves evaluating the thermal stability for the as prepared sample and of samples purified by acid oxidation at $40^{\circ} \mathrm{C}, 60^{\circ} \mathrm{C}$ and $100^{\circ} \mathrm{C}$ (ox-MWCNT@40,ox-MWCNT@60,ox-MWCNT@100 respectively). 
and the temperature of oxidation. This residue is the metal catalyst which cannot be oxidized at temperature of $900^{\circ} \mathrm{C}$. Acid treatment at $100^{\circ} \mathrm{C}$ was the most effective in removing metal impurities. The residual masses of $o x$-MWCNT $\mathrm{M40}, o x-\mathrm{MWCNT}_{\oplus 60}$ and $o x$-MWCNT $\mathrm{M}_{100}$ in thermo-gravimetric analysis are 18,10 and $0 \%$, respectively (Table 2) and it was observed that the higher the temperature of oxidation the lower the residual metal. The lower inflexion temperature of the acid treated CNTs is due to the defects and functionalization moieties on nanotubes walls. However, the excellent thermal stability $\left(\mathrm{T}>550^{\circ} \mathrm{C}\right)$ indicates that the nanotubes are not significantly damaged by the purification process.

The modal length of the large bundles dropped from an average of 1784,1217 to $760 \mathrm{~nm}$ following a standard functionalization procedure of sonication in a mixture of $\mathrm{H}_{2} \mathrm{SO}_{4}$ and $\mathrm{HNO}_{3}$ at 40,60 and $100^{\circ} \mathrm{C}$, respectively. The size, percentage of residual material and morphology of the acid treated MWCNT samples were not affected by the amidation sequence yielding the drug loaded MWCNTs (Figure 3). A decrease in the agglomeration was, however observed as the occurrence of CNTs clusters on TEM images reduced.

The Raman analysis showed that there was no significant change that occurred to the structure due to the acid functionalization or conjugation of the drug to the CNTs as there was a similarity in the peaks as shown in Figure 4 . The D-band is at $1355 \mathrm{~cm}^{-1}$, giving convincing indication for MWCNT origin. The D-band represents the $\mathrm{sp}^{3}$ bonds (tetrahedral configurations) while the G-band is attributed to a C-C stretching mode of well graphitized CNTs and $\mathrm{sp}^{2}$ bonds (planar configurations). The D-band intensity represents the existence of defects and other disorder-induced effects for any type of carbon.

The increase in the ratio of the D-band intensity to the $\mathrm{G}$ band intensity $\left(\mathrm{I}_{\mathrm{D}} / \mathrm{I}_{\mathrm{G}}\right)$ was the key evidence for sidewall functionalization, due to the increased $\mathrm{sp}^{3}$-content in the $\mathrm{sp}^{2}$ framework of the MWCNT sidewalls. As expected, the introduction of functional groups increased the $I_{D} / I_{G}$ ratio of the samples. The increase in the ratio of the $D$ band intensity to the $G$ band intensity $\left(\mathrm{I}_{\mathrm{D}} / \mathrm{I}_{\mathrm{G}}\right)$ from 0.886 for as prepared MWCNTs to 0.898 for $o x$-MWCNT ${ }_{\oplus 40} 1.01$ for $o x-$ MWCNT $_{\odot 60}$ and 1.04 for $o x-\mathrm{MWCNT}_{\oplus 100}$ is the key evidence for sidewall functionalization and reduction in structural order. The same trend was observed for the drug loaded MWCNTs (Table 2) verifying the increase in functionalization due to the conjugation of riluzole.

The BET analysis showed that there was an increase in surface area from Riluzole-MWCNT ${ }_{\circledast 40}$ to Riluzole-MWCNT ${ }_{\circledast 100}$ (Table 2).

\begin{tabular}{|c|c|c|c|c|}
\hline \multirow[t]{2}{*}{ Sample } & \multirow{2}{*}{$\begin{array}{l}\text { [COOH] loading } \\
\text { (mmols/100mg) }\end{array}$} & \multicolumn{2}{|l|}{ Riluzole } & \multirow{2}{*}{$\begin{array}{l}\text { DIC } \\
(\mu \mathrm{I})\end{array}$} \\
\hline & & Mass/mg & mmols & \\
\hline OX-MWCNT & 0.011 & 3.86 & 0.016 & 1.72 \\
\hline Ox-MWCNT @40 & 0.0198 & 6.96 & 0.030 & 3.10 \\
\hline Ox-MWCNT & 0.0356 & 12.51 & 0.053 & 5.57 \\
\hline
\end{tabular}

Table 1: $\mathrm{COOH}$ loading as calculated from the acid-base titrations and amounts of riluzole and DIC used during the amidation process.

\begin{tabular}{lllll}
\hline Sample & $\begin{array}{l}\text { Length } \\
\text { (nm) }\end{array}$ & $\begin{array}{l}\text { Surface Area } \\
\mathbf{m}^{2} / \mathbf{g}\end{array}$ & $\mathbf{R M}^{\mathbf{b}} \mathbf{( \% )}$ & ID/IG $^{\mathbf{c}}$ \\
\hline riluzole-MWCNT & 1784 & 32.6 & 14.8 & 0.91 \\
riluzole-MWCNT $_{@ 60}$ & 1217 & 55.2 & 9.7 & 1.02 \\
riluzole-MWCNT $_{@ 100}$ & 760 & 75.3 & 0 & 1.23 \\
\hline
\end{tabular}

Table 2: Summary of physicochemical properties of the drug loaded MWCNTs. Average lengths of riluzole-MWCNT ${ }^{4}$, riluzole-MWCNT ${ }^{60}$, riluzole-MWCNT were determined from TEM images, respectively b) Residual mass (\%) after thermo-gravimetric analysis (TGA) C). The ratio of Raman D band $\left(1350 \mathrm{~cm}^{-1}\right)$ and $\mathrm{G}$ band $\left(1580 \mathrm{~cm}^{-1}\right)$ peak height at wavelength $532 \mathrm{~nm}$.
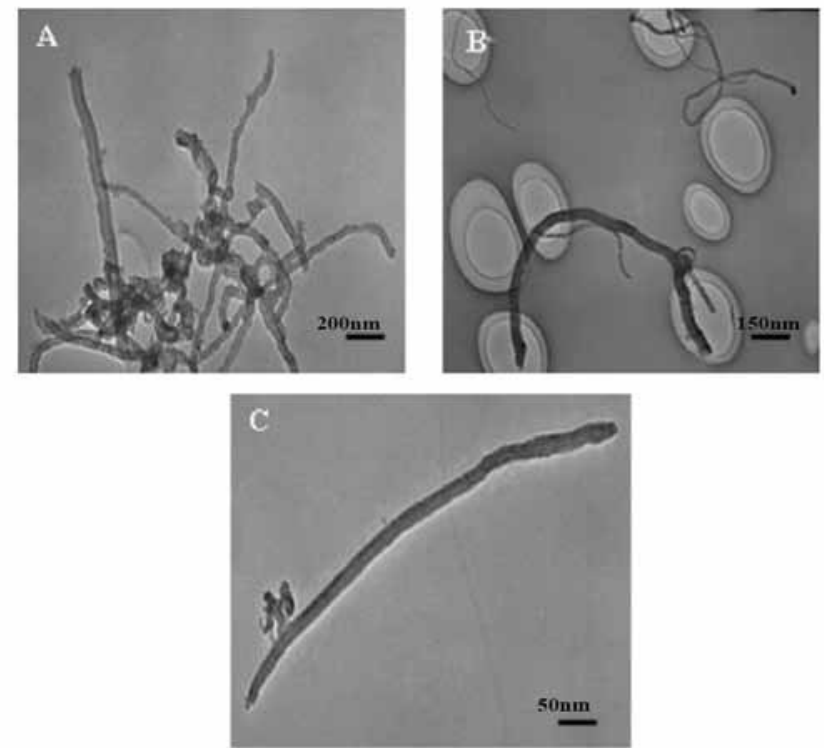

Figure 3: TEM images showing the morphology of riluzole loaded carbon nanotubes. Image a) riluzole-MWCNT $\mathrm{M40}_{0}$ b) riluzole-MWCNT $\mathrm{M60}$ c) riluzoleMWCNT $@ 100$

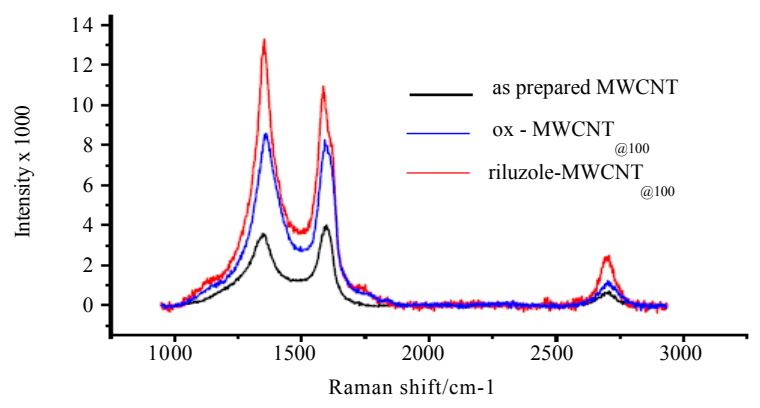

Figure 4: Raman graphs for as prepared MWCNTs, acid treated MWCNTs and drug loaded MWCNTs using a $514.5 \mathrm{~nm}$ line of an argon ion laser.

This may be explained by the fact that as the temperature of oxidation increased agglomeration and length were reduced. As agglomeration (number of tubes in a bundle) and length decrease the surface area is known to increase. This is in agreement with what Peigney et al. [3] reported. They calculated the external surface area of CNTs and found that as the number of CNTs making a bundle decreased the surface area increased.

\section{Verification of the success of conjugation}

The acid treatments produced carboxylic acid groups $(\mathrm{COOH})$ and/or hydroxyl groups $(\mathrm{OH})$ on surface of CNTs via oxidations of double bonds in the graphene wall as confirmed by the FTIR. The peaks at around $3400 \mathrm{~cm}^{-1}$ corresponded to the infrared absorption of the H-bonded hydroxyl groups. The peak at around $1735 \mathrm{~cm}^{-1}$ corresponds to the $\mathrm{C}=\mathrm{O}$ stretch of acid carboxyl. The formation of amide functionalities in MWCNT-riluzole conjugate, was evidenced by the disappearance of the $1735 \mathrm{~cm}^{-1}(\mathrm{C}=\mathrm{O}$ stretch of carboxyl) and the appearance of $1670 \mathrm{~cm}^{-1}(\mathrm{C}=\mathrm{O}$ stretch of amide carbonyl). Peaks at $1548 \mathrm{~cm}^{-1}$ are attributed to the stretch of $\mathrm{C}-\mathrm{N}$ and bend of $\mathrm{N}-\mathrm{H}$ in amide. The peaks at $1113 \mathrm{~cm}^{-1}$ (corresponding to $\mathrm{C}-\mathrm{O}-\mathrm{C}$ ether 
group), $900 \mathrm{~cm}^{-1}$ (corresponding to C-F stretch) adsorptions and 3033 $\mathrm{cm}^{-1}$ (corresponding to aromatic $\mathrm{C}-\mathrm{H}$ stretching), represent functional groups in the riluzole structure.

The success of conjugation was further confirmed by a UV-vis analysis of the riluzole loaded MWCNTs. Free riluzole in methanol has an absorption peak at 290-310 nm wavelength (Figure 5A) whilst acid oxidized MWCNTs have an absorption peak at $220 \mathrm{~nm}$ (Figure 5B). The UV-vis spectrum of riluzole loaded MWCNTs in methanol exhibit the typical absorption bands of riluzole in the range $280-290 \mathrm{~nm}$ and those of oxidized MWCNTs at $220 \mathrm{~nm}$ (Figure 5B).

\section{Uptake of FITC labelled CNT-riluzole by PC12 neuronal Cells}

After the incubation the cells were washed by centrifugation and the fluorescence intensity for both the cells and the supernatant was determined by the Victor X3. The translocation efficiency was calculated as follows

$$
\% \text { Translocation }=\frac{\text { Flourescence intensity inside cells }}{\text { Total Flouresence }}
$$

Where, the total fluorescence is the sum of the fluorescence intensity for cells and for the supernatant. Both intensities are after background correction. The delivery efficiency in this experiment for the highest concentration of $0.2 \mathrm{mg} / \mathrm{ml}$ was $95 \%$ (Figure 6), suggesting that all cells had taken up the CNT-riluzole-FITC conjugate. FITC only control was performed to corroborate these findings. Figure 6 shows a low level of fluorescence, thus indicating that FITC only is able to enter into cells to a very small extent, which demonstrates that CNTs play an important role as a delivery system in rapidly and efficiently delivering the drug into the cells.

\section{Physicochemical effects on the toxicity of riluzole loaded MWCNTs}

The three drug loaded MWCNT: riluzole-MWCNT ${ }_{\odot 40}$, riluzole$\mathrm{MWCNT}_{₫ 60}$, riluzole-MWCNT ${ }_{\oplus 100}$ samples were modified according to routes that decoupled key physicochemical and structural properties, including length, catalytic metal content, aggregation state, and surface chemistry. Properties with suspected relevance cytotoxicity are summarized in Table 2.

In vitro studies to assess the cytotoxic capability of the riluzoleMWCNT conjugates using the PC12 neuronal cells showed that the alteration of the physicochemical properties of the MWCNTs due to purification and functionalization procedures had no effect on MWCNTs' toxicity in neuronal cells. Indeed short nanotubes with surface area $\left(30-80 \mathrm{~m}^{2} / \mathrm{g}\right)$ and with $<15 \%$ metal impurities were not cytotoxic to neuronal cells (Figure 7). As displayed in Figure 7, no significant loss of cell viability upon incubation of the cell with 0.002 $0.2 \mathrm{mg} / \mathrm{ml}$ of drug loaded MWCNTs for 24 hours was observed, as compared to untreated cells. There was a statistical significance of drug loaded MWCNT samples $[\mathrm{F}(2,4)=7.70, \mathrm{p}=0.04]$ and concentration effect $[\mathrm{F}(2,4)=7.92, \mathrm{p}=0.04]$ at $95 \%$ confidence level.

Cell viability was judged by morphological changes or by changes in membrane permeability inferred from the exclusion or the uptake and retention of tetrazolium salt. Live cells with intact membranes are distinguished by their ability to exclude tetrazolium salt that easily penetrates dead or damaged cells and converts into a red formazan dye in the presence of LDH. Nonviable cells will have higher absorbances at $490 \mathrm{~nm}$ wavelength (formazan is detected at wavelength of $490 \mathrm{~nm}$ ) than the, viable cells. The relative absorbances obtained showed that the cell death in the control due to normal LDH release was almost similar to that of cells treated with the drug loaded MWCNTs (Figure 7).

The drug loaded MWCNTs had a high degree of functionalization as evidenced by the high $\mathrm{D} / \mathrm{G}$ ratio (Table 2 ) and showed no toxicity in the neuronal cells. The result suggests that change in the surface chemistry of the MWCNTs did not result in them being toxic. This is in agreement with Sayes et al. [17] who reported that the cytotoxicity of covalently modified CNTs decreases with increase in the degree of sidewall functionalization. However the intrinsic toxicity of CNTs does not depend only on the degree of surface functionalization.

Long and rigid CNT (high aspect ratio) have been found to increase the risk of radical oxygen species generation and inflammatory response stimulation, $[27,28]$. In this study the shorter riluzole-MWNT ${ }_{@ 100}$ did not display a significantly higher toxicity than longer riluzole-
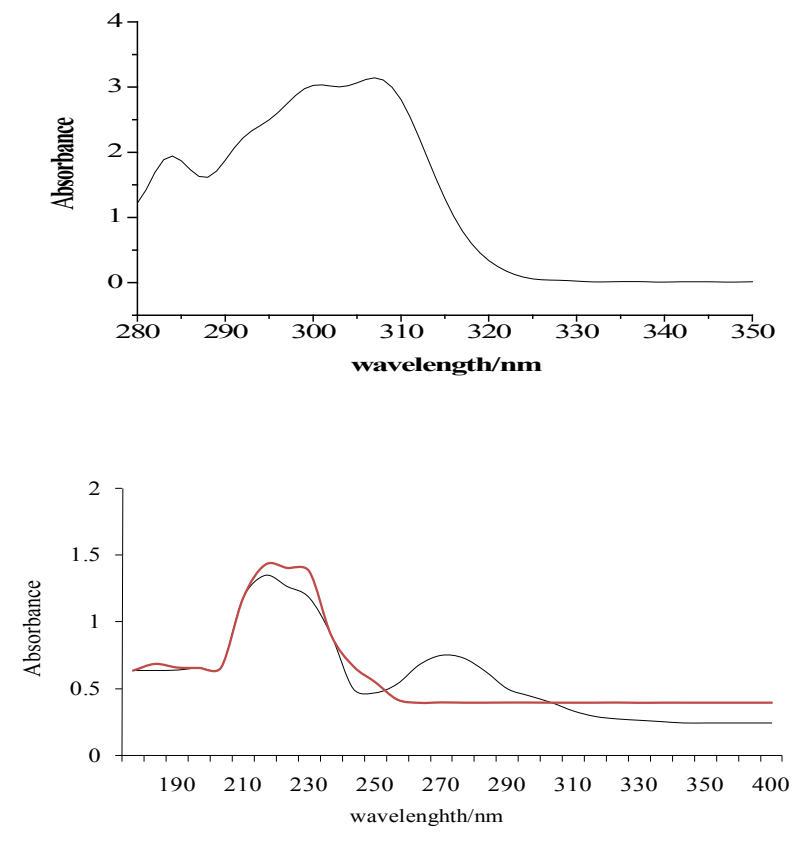

Figure 5: Spectroscopic monitoring of the conjugation of the drug. The curves represent $(A)$ the profile of unconjugated riluzole, (red line) acid oxidized MWCNTs and (black) riluzole loaded MWCNTs. Characteristic peaks at $280 \mathrm{~nm}$ demonstrate the successful conjugation of the drug to the MWCNTs.

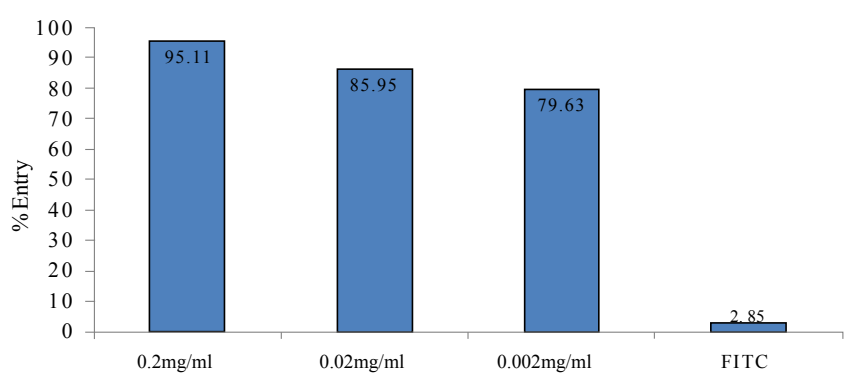

Figure 6: Dose response of the internalization after neuronal cells are incubated at $37^{\circ} \mathrm{C}$ with FITC labeled riluzole loaded MWCNTs respectively in comparison to control cells treated with FITC in the absence of the MWCNTs. 
MWCNT $_{\odot 40}$. This can be explained by the fact that even though the riluzole-MWCNT $\mathrm{Q40}_{04}$ is longer relative to the other samples they still fall under the short range. Long tubes can be defined as tubes that significantly exceed the size of macrophages and are usually taken to be $>20 \mu \mathrm{m}$ long [28]. It is impossible to have longer tubes due to the acid oxidation step which was necessary to introduce the carboxylic groups which were a platform for the drug conjugation, however, it shortens CNTs to as short as $140 \mathrm{~nm}$ [12] depending on conditions.

Intrinsic toxicity of CNTs has been shown to depend on the presence of impurities such as amorphous carbon and metallic nanoparticles (catalysts: $\mathrm{Co}, \mathrm{Fe}, \mathrm{Ni}$ and $\mathrm{Mo}$ ) which are introduced during synthesis [19]. However, in this study catalytic metal (Fe) content in the drug loaded MWCNT samples does not significantly affect their toxicity. Indeed, riluzole-MWCNT ${ }_{\oplus 40}$ which had as much as $15 \%$ impurities, exhibited no toxicity in cell membrane integrity assays similar to the riluzole-MWCNt ${ }_{\oplus 60}$ which had $50 \%$ less metal impurities and riluzoleMWCNT $_{\oplus 100}$ which had $100 \%$ less content. The apparent inconsistency between this study's data and previous studies correlating residual catalytic metal in unpurified CNTs to elevated toxicity in human epidermal keratinocytes [19] may stem from the relatively lowmetal content of the samples ( $<15 \%$, compared to $30 \%$ in the Shvedova et al. [19] study).

It would appear that the riluzole loaded MWCNTs with at least 30\% metal residue are required to produce cytotoxic effects. Alternatively, residual catalytic metals may damage eukaryotic cell lines through pathways that do not damage the neuronal cell lines. Pulskamp et al. [20] reported a similar result to this study. They did not observe any acute toxicity on cell viability upon incubation with unpurified SWCNTs ( $8 \%$ impurities), purified SWCNTs (2.5\% impurities), and purified MWCNT (5\% impurities) in rat alveolar macrophages.

\section{Effect of MWCNT-riluzole on glutamic acid induced neuronal injury}

In the Glutamic acid treated control, brief exposure of cultured neurons to $0.25 \mathrm{mM}$ Glutamic acid was sufficient to cause marked neuronal damage as indicated from comparing the $\mathrm{LDH}$ released of untreated cells $(60 \%)$ and that of Glutamic acid treated cells in the absence of riluzole or riluzole-MWCNT ${ }_{\oplus 100}(100 \%)$, (Figure 8).

The percentage relative neuronal death was calculated as follows

$$
\% L D H \text { release }=\text { Mean } L D H \text { released / Maximum } L D H \text { released }
$$

Where the maximum $\mathrm{LDH}$ release was taken to be the $\mathrm{LDH}$ released in the cells treated with Glutamic acid only in the absence of the drug loaded MWCNTs and riluzole. There was a statistical significance of riluzole-MWCNT ${ }_{@ 100}$, riluzole and $o x-\mathrm{MWCNTs}, \mathrm{F}=78.52$ at $95 \%$ confidence level. The main effect for concentration did not reach statistical significance, $\mathrm{F}=1.016$ at $95 \%$ confidence level.

Glu at $0.25 \mathrm{mM}$ increased LDH release by about $40 \%$ above the control whereas in riluzole-MWCNT ${ }_{@ 100}$ and riluzole protected groups, LDH release was reduced to less than that of the untreated cells control. In the group treated with Glutamic acid in the presence of $0.1 \mu \mathrm{M}$ riluzole-MWCNT ${ }_{@ 100}$, the neuronal viability appears to be best preserved (Figure 8), with an LDH release of $42 \%$ compared to the $53 \%$ for the $10 \mu \mathrm{M}$ and $1 \mu \mathrm{M}$. The antiglutamic activity of $0.1 \mu \mathrm{M}$ riluzole-MWCNT $\mathrm{M}_{\oplus 100}(42 \% \mathrm{LDH}$ released) is comparable to that of free riluzole ( $40 \% \mathrm{LDH}$ released). This suggests that $0.1 \mu \mathrm{M}$ riluzoleMWCNT $_{\oplus 100}$ may have protective function against Glu-induced neuronal injury which is comparable to that of riluzole. Furthermore,

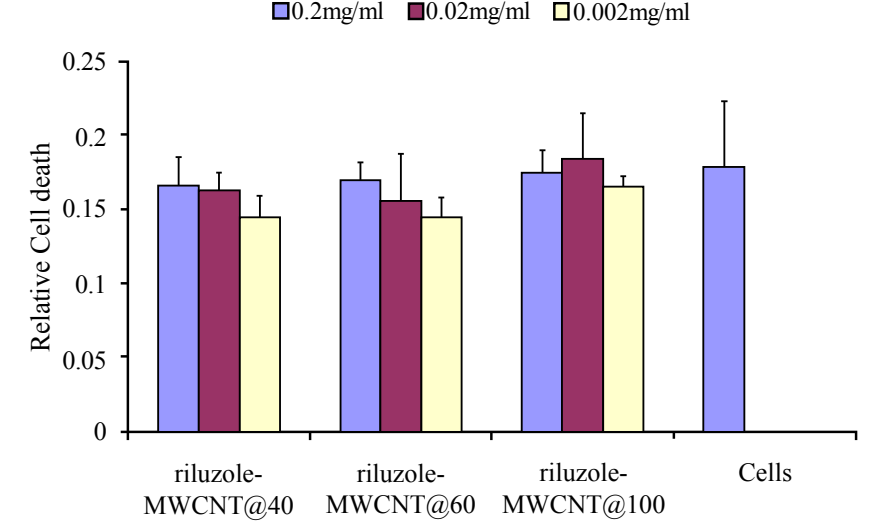

Figure 7: Comparison of cytotoxity of varying concentrations and different degrees of functionalization of the drug loaded MWCNTs as compared to the untreated cells using the CytoTox $96^{\circledR}$ Non-Radioactive Cytotoxicity Assay in PC12 neuronal cells. Values are expressed as mean \pm SD. Statistically significant difference is indicated by $p$-value $<0.05$ when compared to the control.

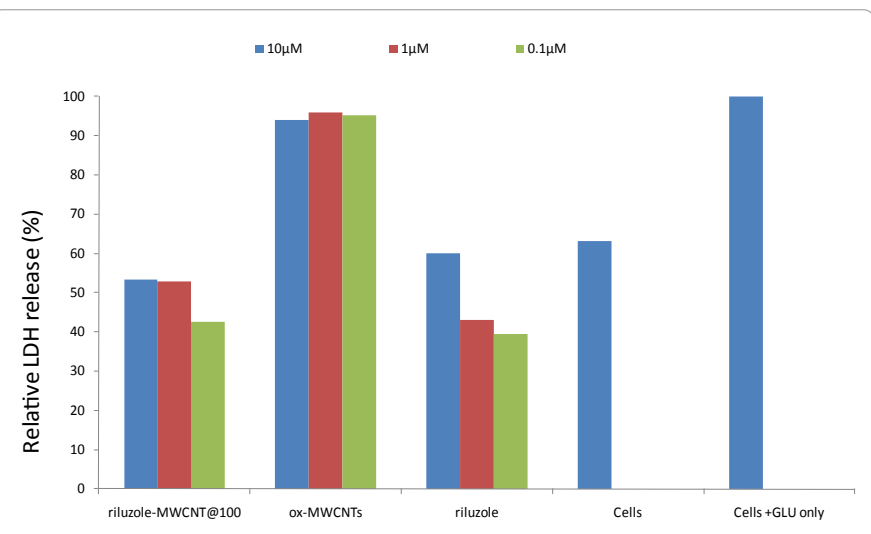

Figure 8: Anti glutamate activity of the riluzole loaded MWCNTs evaluated by release of lactate dehydrogenase (LDH) from damaged neuronal cells. $\mathrm{LDH}$ activities were measured spectrophotometricaly by monitoring the changes of absorbance at $490 \mathrm{~nm}$. Controls include ox-MWCNTs and unconjugated riluzole. Means are significantly different $(\mathrm{P}<0.05)$

the neuroprotective function of riluzole-MWCNT ${ }_{\circledast 100}$ against Gluinduced neurotoxicity appears to be dose-dependent reducing $\mathrm{LDH}$ release from $53 \%$ to $42 \%$ at 10,1 and $0.1 \mu \mathrm{M}$ riluzole-MWCNT $\mathrm{M}_{\oplus 100}$ respectively (Figure 8).

This is consistent with the results that have been reported on the antiglutamic effect of riluzole and the optimal concentration necessary for effective preservation of cells from excitotoxicity. Azbill et al. [29] found out that the rate of glutamate uptake was significantly increased in the presence of $0.1 \mu \mathrm{M}$ and $1.0 \mu \mathrm{M}$ riluzole, but not at the higher concentrations examined.

\section{Conclusion}

The data from this study supports the hypothesis that physicochemical modifications of MWCNTs that occur due to the functionalization of the drug to its surfaces alter their toxicity in neuronal systems. The riluzole loaded MWCNTs with $<15 \%$ metallic residue, 500-2000 nm length, and surface areas $\left(30-76 \mathrm{~m}^{2} / \mathrm{g}\right)$ were found not to cause toxic effects as all the cells were viable compared to the untreated cells control. This suggests that covalently linking riluzole to MWCNTs 
Citation: Chigumbu N, lyuke S, Pillay V, Ndlovu S (2012) In Vitro Evaluation of the Physicochemical Effects of Drug Loaded Carbon Nanotubes on Toxicity. J Nanomed Nanotechol 3:135. doi:10.4172/2157-7439.1000135

and the subsequent changes in the physicochemical properties does not lead to the generation of toxic effects in cells. The rapid internalization of the riluzole by carbon nanotubes in a non-toxic manner coupled with the neuroprotectiveness will be particularly advantageous for an improved efficiency of the drug action. The identification of specific physicochemical properties governing CNTs toxicity presents the opportunity for carbon nanotube based drug delivery system designs or applications that reduce human and environmental impacts.

\section{Acknowledgements}

The authors would like to acknowledge to the NRF, Nanotechnology flagship grant and the University of Witwatersrand's Postgraduate Merit Award for their unwavering financial support towards this research.

\section{References}

1. Thostenson ET, Ren Z, Chou TW (2001) Advances in the science and technology of carbon nanotubes and their composites: A review. Compos Sci Technol 61: 1899-1912.

2. Jorio A, Saito R, Hafner JH, Lieber CM, Hunter M, et al. (2001) Structural (n $\mathrm{m}$ ) determination of isolated single-wall carbon nanotubes by resonant Raman scattering. Phys Rev Lett 86: 1118-1121.

3. Peigney A, Laurent Ch, Flahaut E, Bacsa RR, Rousset A (2001) Specific surface area of carbon nanotubes and bundles of carbon nanotubes. Carbon 39: $507-514$

4. Hughes JT (1982) Pathology of amyotrophic lateral sclerosis. Adv Neurol 36: 61-74.

5. Williams DB, Windebank AJ (1991) Motor neuron disease (amyotrophic lateral sclerosis). Mayo Clin Proc 66: 54-82.

6. Kurtzke JF (1982) Epidemiology of amyotrophic lateral sclerosis. Adv Neurol 36: 281-302.

7. Schepelmann K, Winter Y, Spottke AE, Claus D, Grothe C, et al. (2010) Socioeconomic burden of amyotrophic lateral sclerosis, myasthenia gravis and facioscapulohumeral muscular dystrophy. J Neurol 257: 15-23.

8. Bensimon G, Lacomblez L, Meininger V (1994) A controlled trial of riluzole in amyotrophic lateral sclerosis. N Engl J Med 330: 585-591.

9. Traynor BJ, Alexander M, Corr B, Frost E, Hardiman O (2003) An outcome study of riluzole in amyotrophic lateral sclerosis: A population-based study in Ireland, 1996-2000. J Neurol 250: 473-479.

10. Allen TM, Cullis PR (2004) Drug Delivery Systems: Entering the Mainstream. Science 303: 1818-1822.

11. Bianco A, Kostarelos K, Prato M (2005) Applications of carbon nanotubes in drug delivery. Curr opin chem biol 9: 674-679.

12. Wu W, Wieckowski S, Pastorin G, Benincasa M, Klumpp C, et al. (2005) Targeted delivery of amphotericin B to cells by using functionalized carbon nanotubes. Angew Chem Int Ed Engl 44: 6358-6362.

13. Kang S, Mauter MS, Elimelech M (2008) Physicochemical determinants of multiwalled carbon nanotube bacterial cytotoxicity. Environ Sci Technol 42 $7528-7534$.

14. Poland CA, Duffin R, Kinloch I, Maynard A, Wallace WA, et al. (2008) Carbon nanotubes introduced into the abdominal cavity of mice show asbestos-like pathogenicity in a pilot study. Nat Nanotechnol 3: 423-428.

15. Hirano S, Kanno S, Furuyama A (2008) Multi-walled carbon nanotubes injure the plasma membrane of macrophages. Toxicol Appl Pharmacol 232: 244-251.

16. Tian F, Cui D, Schwarz H, Estrada GG, Kobayashi H (2006) Cytotoxicity of single-wall carbon nanotubes on human fibroblasts. Toxicol in Vitro 20: 1202 1212.

17. Sayes CM, Liang F, Hudson JL, Mendez J, Guo W, et al. (2006) Functionalization density dependence of single-walled carbon nanotubes cytotoxicity in vitro. Toxicol Lett 161: 135-142.

18. Dumortier H, Lacotte S, Pastorin G, Marega R, Wu W, et al. (2006) Functionalized carbon nanotubes are non-cytotoxic and preserve the functionality of primary immune cells. Nano lett 6: 1522-1528.

19. Shvedova AA, Castranova V, Kisin ER, Schwegler-Berry D, Murray AR, et al. (2003) Exposure to carbon nanotube material: Assessment of nanotube cytotoxicity using human keratinocyte cells. J Toxicol Environ Health A 66 1909-1926.

20. Pulskamp K, Diabate S, Krug HF (2007) Carbon nanotubes show no sign of acute toxicity but induce intracellular reactive oxygen species in dependence on contaminants. Toxicol Lett 168: 58-74.

21. Powers KW, Palazuelos M, Moudgil BM, Roberts SM (2007) Characterization of the size, shape, and state of dispersion of nanoparticles for toxicological studies. Nanotoxicol 1: 42-51.

22. Pastorin G, Wu W, Wieckowski S, Briand JP, Kostarelos K, et al. (2006) Double functionalization of carbon nanotubes for multimodal drug delivery. Chem Commun : 1182-1184.

23. Iyuke SE, Abdulkareem SA, Afolabi SA, Piennar CHV (2007) Catalytic production of carbon nanotubes in a swirled fluid chemical vapour deposition reactor. International Journal of Chemical Reactor Engineering 5.

24. Li Y, Zhang X, Luo J, Huang W, Cheng J, et al. (2004) Purification of CVD synthesized single-wall carbon nanotubes by different acid oxidation treatments. Nanotechnol 15: 1645-1649.

25. Chen JP, Lin M (2001) Surface charge and metal ion adsorption on an H-type activated carbon: Experimental observation and modeling simulation by the surface complex formation approach. Carbon 39: 1491-1504.

26. Ramesh BP, Blau WJ, Tyagi PK, Misra DS, Ali N, et al. (2006) Thermogravimetric analysis of cobalt-filled carbon nanotubes deposited by chemical vapour deposition. Thin Solid Films 494: 128-132.

27. Kim JS, Song KS, Joo HJ, Lee JH, Yu IJ (2010) Determination of cytotoxicity attributed to multiwall carbon nanotubes (MWCNT) in normal human embryonic lung cell (WI-38) line. J Toxicol Environ Health A: Current Issues 73: 1521 1529.

28. Sato Y, Yokoyama A, Shibata KI, Akimoto Y, Ogino S, et al. (2005) Influence of length on cytotoxicity of multi-walled carbon nanotubes against human acute monocytic leukemia cell line THP-1 in vitro and subcutaneous tissue of rats in vivo. Mol Biosyst 1: 176-182.

29. Azbill RD, Mu X, Springer JE (2000) Riluzole increases high-affinity glutamate uptake in rat spinal cord synaptosomes. Brain res 871: 175-180. 